\title{
Avoiding Irrelevance:
}

\section{The manifestation and impacts of technophobia in psychological science}

\author{
Davidson, B. I. ${ }^{1}$, Ellis, D. A. ${ }^{2}$, Bowman, N. D. ${ }^{3}$, Liveley, $\mathbf{G}^{4}$, \\ Shaw, H. ${ }^{5}$, Przybylski, A. K. ${ }^{6,7}$, \& Levine, M. ${ }^{5}$ \\ ${ }^{1}$ Department of Computer Science, University of Bristol, UK \\ ${ }^{2}$ School of Management, University of Bath, UK, \\ ${ }^{3}$ Media and Communication, Texas Tech University, USA, \\ ${ }^{4}$ School of Humanities, University of Bristol, UK \\ ${ }^{5}$ Department of Psychology, Lancaster University, UK \\ ${ }^{6}$ Oxford Internet Institute, University of Oxford, UK \\ ${ }^{7}$ Department of Experimental Psychology, University of Oxford, UK
}

\begin{abstract}
New technologies continue to provide a wealth of opportunities for society. However, in recent years the discipline of psychological science has focused greater attention on how these technologies are likely to harm rather than to help large sections of the population. Despite these warnings from psychological science, as technologies become mass-adopted, initial fears concerning their negative potential are later revealed to have been inaccurate, irrelevant, or overshadowed by positives of these technologies. Here, we investigate whether the discipline of psychological science may have become a victim of technophobic bias in its treatment of the social harms threatened by some new technologies, while avoiding suffering from techno-optimism. Paradoxically, while psychology should be well positioned to understand, explain, and potentially mitigate any negative social impacts of new technology, it has - to date - had comparatively little to contribute to public policy and debate compared to analogous disciplines in the social sciences. Taking so-called 'addiction' to personal smartphone use as a case study, we argue that by examining and addressing some of the biases evident in its own approach to sociotechnical innovation, psychology has much to offer in terms of the broader debate of the psychological impacts of emerging technologies. We conclude by providing some recommendations on how the discipline can become more productive, break free of current myopic research cycles, and make a stronger and more comprehensive contribution to the future of sociotechnical innovation.
\end{abstract}




\section{Introduction}

'There will come a time when it isn't 'They're spying on me through my phone' anymore. Eventually, it will be 'My phone is spying on me.'.' (Phillip K. Dick)

'All too often, it is easier to focus on the technology than the broader systematic issues that are at play because the technical changes are easier to see,' (boyd, 2014, p. 16)

The history of technology is also a history of fear. Of course, fear certainly is an important response across evolution, for example, it has been linked to 'fight or flight' or the 'freeze' response to danger (Bracha, Williams, \& Bracha, 2004). However, these very fears can also be misplaced. Plato's Socrates once argued that the invention of the alphabet would result in memory impairment (Plato, Phaedrus 274c-277a). Two thousand years later, it is still debated whether the Greek alphabet was indeed directly responsible for a fundamental change in the cognitive and social psychology of the ancient Athenians (McLuhan and Logan 1977), resulting in the 'deep psychological crisis' (Kerckhove and Lumsden 1988) that inspired the great Greek tragedies of the classical period. Even the grandparent of modern electronic communications - the telephone - caused great concern when it first entered the home and workplace. Many were worried it could make them deaf or mentally ill (Parker, 1995), and early telephony faced general public criticism as an unnecessary and dangerous innovation (Stein, 1996). Like other innovative technologies, the telephone disrupted traditional business models and transformed the way we live (Fischer, 1992). This disruptive innovation has become increasingly the norm, from the telephone to the digital camera, where it is not a matter of these fears of technological change disappearing, we as the consumer and end-users adapt and adopt these technologies as a process of acclimation. While this initial widespread fear of the telephone dramatically slowed adoption in the early years and led to significant - and unnecessary — worry, this technology, among many others have been highly successful (Parker, 1995).

This technophobia appears to repeat with the introduction of every new mass adopted technology (Table 1), which is arguably related to Gartner's Hype Cycle. This suggests that the 'Trough of Disillusionment' (Gartner, 2020; Thierer, 2013) may coincide with repetitive moral techno-panics. Thierer (2013, pp. 311) defined this as 'public, political, and academic responses to the emergence of use of media technologies, especially by the young,' —where this starts as focusing on new forms of media (e.g., smartphones), leading 
to pathologizing their use, then leading to widespread anxiety in the hope of nudging or adapting young person's behavior with various devices. More recently, the increased adoption of mobile technology in the early 21 st century even led to a UK Government enquiry that considered evidence on the negative effects of social media, screen-time, and smartphone usage in young adults. Unfortunately, they concluded that the poor quality of academic evidence available — much of it from psychology — limited their ability to draw strong conclusions (UK Parliament, 2018). While it is not the intention of this paper to cast aspersion on the general quality of such research in psychology, the fact that psychological science apparently cannot be depended upon to contribute to meaningful public policy debates in this context is troubling - especially given that the focal debate is one so clearly rooted in psychological harm (or at least, fear of such harms). The discussion and analysis seeks to investigate why this might be the case, and suggests some positive ways to address the issue to improve future contributions, where we focus primarily on smartphones as a leading example throughout this piece.

Table 1. Examples of communication technologies that faced initial public fears

Decade Technology Reason for fear

\begin{tabular}{|c|c|c|}
\hline c400 BCE & Writing & $\begin{array}{l}\text { Fear that alphabetic writing would impair memory (Plato, } \\
\text { Phaedrus, } 360 \mathrm{BCE}) \text {. }\end{array}$ \\
\hline $\mathrm{c} 1400 \mathrm{~s}$ & Printing Press & $\begin{array}{l}\text { Fear it would cause laziness as widespread printing } \\
\text { presses meant there was less need for scribes (Dittmar, } \\
2011 \text { ). }\end{array}$ \\
\hline $1800 \mathrm{~s}$ & Telephone & $\begin{array}{l}\text { Feared that it would make users deaf or mentally ill } \\
\text { (Parker, 1995). }\end{array}$ \\
\hline 1960 s on & TV & $\begin{array}{l}\text { Feared it would cause a lack of imagination in children. } \\
\text { Further, due to the new violent films airing, it was feared } \\
\text { these would act as an instruction manual for others to } \\
\text { engage in violent behavior (U.S. Department of } \\
\text { Education, 1982). }\end{array}$ \\
\hline
\end{tabular}


1970s on

1980s

1990s

$2000 s$

First Video Game: PONG Video games were considered addictive (Soper \& Miller, 1983). Later, with the production of violent video games (e.g., Death Race), it was feared they would also cause violent behavior (Blumenthal, 1976; Korucek, 2012).

Personal Computers

WiFi

Smartphones
There was a widespread 'computerphobia'-fear of not knowing how to use them and fear of being replaced by them (Rosen \& Sears, 1987).

Feared WiFi could cause cancer from electromagnetic waves (Goldsworthy, 2011).

Feared users will become addicted to their smartphone. Further, they may cause anxiety, depression, and decrease social interaction (e.g., Elhai, Dvorak, Levine, \& Hall, 2017; Richardson, Hussain, \& Griffiths, 2018).

Current fear of 'secondhand screen time', which is as devastating as secondhand smoke (Renstrom, 2020).

The current body of research from psychological science, with few exceptions, follows a pattern where initial concerns over a new piece of technology (such as the smartphone) develop into psychological research that appears to confirm inherent dangers or potential harms posed by a new device or service (e.g., Elhai et al., 2017; Griffiths, 2005, Richardson et al, 2018; Tao et al., 2017; Wolneiwicz, 2018). This is, perhaps, a result of researchers not focusing on more generic, descriptive, and 'basic' research regarding technology and society, coupled with a tendency for psychological research to focus on identifying and positing mitigations to threats and risks to humans (Rutledge, 2013). While this likely relates to psychological theory can often focus more on mitigating threats, which inherently primes psychologists to focus more on fear than perhaps other perspectives. Hence, the widespread focus in the research upon 'proving' normative assumptions (e.g., that a new technology is inherently 'bad'), typically leads to attempts to explain the negative impacts of a given technology rather than attempts to question whether those threats are real in the first place. Indeed, many technophobic concerns are quickly forgotten by society and psychologists alike, as anticipated negative threats are shown to be overinflated or demonstrably false 
(e.g., Van Rooij et al, 2018). The debate then moves on (or rather, repeats) as fears over one piece of new technology are allayed but are then replaced by fresh concerns about a new(er) technology. This pattern has recently played out in the context of social media and smartphones, which (according to the latest psychological research) might not be as dangerous as previously suggested (e.g., Orben, Dienlin, \& Przybylski, 2019; Orben \& Przybylski, 2019b, 2019a). This constant (re)cycling of technophobia within psychological research suggests that the stories that psychologists most often like to tell (and funders fund) about technology and innovation are predominantly dystopian.

\section{Eternal Return...}

New technology can readily appear as a threat to society, because it brings with it the prospect of change. It can change values, the way society works, the interpersonal and cultural structures present within it, and impact upon jobs and livelihoods (Fieschi, 2002; Green, 2012). For instance, the microprocessor when introduced at scale transformed industry (and subsequently in the 1980s, computers became more integrated into workplaces). This led to pay increases for those working more with computers but replaced many who were not re-skilled (Autor, Katz, \& Alan, 1998; Green, 2012). Politically, this is to be expected, as deskilling of the wider labor-force is arguably critical to economic advancement—'deskilling leads to mechanization' (Feenberg, 2010, p. 42) - as seen during previous innovations in the $19^{\text {th }}$ Century onwards with the industrial revolution (Feenberg, 2010). These dystopian fears can be seen in, and are likely exacerbated by, popular media reporting of technological innovation (Scott, 2018). Broadly, Altheide (1997) explains that there is a significant problem in mainstream media reporting, in which such innovations are presented in narrative form - very often as dystopian visions (appealing to popular science fiction tropes) or as morality plays with clearly anchored antagonists (in the case of these stories, new technologies and scientists represented as the antagonists). Technological innovations are cast as 'folk devils' (Goode \& Ben-Yehuda, 1994, p. 149) and as a result, public technophobia is fueled. This dualism of technology as good or bad, neutral or belligerent, of course does not hold up to scrutiny, where the reality falls between these binary extremes.

While scientific debate is healthy, the above pattern continues to ebb and flow through published psychological research (Davidson \& Ellis, 2019; Ellis, Davidson, \& Kaye, 2019). This is especially problematic when research concerns itself with effects that could have an impact upon a significant proportion of the population and require changes to public policy (Elson et al., 2019). We acknowledge that the speed of technological development presents a challenging environment for both researchers and policymakers wanting to fully understand the uses and effects, for better and for worse, of new sociotechnical devices (such as smartphones) - especially given the accelerated exponential growth that 
technologies follow (Kucharavy \& Guio, 2008). Despite this, there is little doubt that these digital technologies bring psychological benefits, for example, online communities providing support to those suffering with various illnesses, or the ability to communicate with loved ones who reside in other locations - particularly in times of crisis (Katevas, Arapakis, \& Pielot, 2018; Ellis, 2019; Davidson, Joinson, \& Jones, 2018), however the true extent of both these benefits and other potential downfalls are largely unknown. Yet such matters are deserving of rigorous and objective research considering the questions of benefits and harms, especially when new technologies are widely adopted by societies and appear to be becoming integrated across almost all aspects of life (e.g., social, health, and work), noting that of course, the speed at which these technologies change, update, or become obsolete typically outpaces research and our understanding of their impacts (both positive and negative).

To clarify, we are not suggesting that there are no harms associated with new technologies. We are merely challenging the prevailing and a priori assumptions seen in related research conducted within the field psychological science. Physical harms concerning technology are arguably more clear-cut; for instance, using a smartphone while driving or when crossing a road is inherently dangerous as it can result in attentional lapses that can result in immediate bodily harm (Albert \& Lotan, 2018; Brasington, 1990). Other examples might include 'Nintenditis' (Schlink, 1991), which occurs as a result from video gamers (usually, adolescents) suffering acute tendonitis after long sessions of gaming (Brasington, 1990); similar cases have been reported with smartphones and other contemporary handheld devices (e.g., Gilman, Cage, Horn, et al., 2015). However, when we consider psychological harms (such as a technology's impact on individuals' and society's well-being), the assumptions of current knowledge and understanding are overstated, and we have a duty of care to ensure that the science coming from psychologists is rigorous and of a high quality (Shaw et al., 2018). While we may find harms associated with technologies in years to come, the present evidence and knowledge base for such harms is comparatively weak, and we must tread carefully as a discipline when attempting to generalize our current understanding beyond a single technology (e.g., Elhai et al., 2017; Griffiths, 1995; 2005, Richardson et al, 2018; Tao et al., 2017; Wolneiwicz, 2018). One way to do this would be to self-reflexively consider some of the psychological conditions that might be constraining the current focus of psychological research in this area, and to interrogate why it might be the case that so much of the current research in psychology (unlike that in other cognate disciplines) tends to repeat a pattern emphasizing dystopian harm over utopian benefit in its assessment of new technologies.

\section{Is apprehension of technology driving research agendas?}

Within psychological science research, new technologies are sometimes considered as conduits providing something that will transform our lives for the better (e.g., online communities for illness support (Obst \& Stafurik, 2010; Wang, Brede, Ianni, \& Mentzakis, 2018). However, it is important to note that the focus on 
negative impacts of technology receives a disproportionate amount of attention by both researchers and the media that covers this work. This has often been repeatedly spearheaded by those working in domains that appear clinical, but which remain highly disputed including behavioral addictions (e.g., Griffiths, 2019; Twenge, 2019).

Given that these other disciplines appear to present a comparatively balanced view of sociotechnical innovation, are there discipline-specific biases or constraints that are limiting the research scope of work being carried out in the field of psychology? We would argue that a fear of technology can be (at least partially) explained by a number of existing psychological theories and wider perspectives from other disciplines. We provide key examples in Table 2, noting it is not exhaustive. These theories may offer insight as to how and why psychology research on technology inherently focuses on the negative impacts of technology. However, adjacently, it is curious to note that other disciplines (e.g., IS or STS) have drawn also upon psychological theories but have managed to avoid falling victim to the same biases that other areas of social science have been subject to. Many of these concern biases and limitations, which researchers should be aware of and consider when conducting research into sociotechnical innovation. While these 'biases' often serve us well, they are also likely to contribute to why some psychological scientists tend to focus on the potential harms rather than the potential benefits of technology. Hence, examples in Table 2 help explain why members of the public, scientists, and the media tend to focus on technological concerns rather than benefits in the short term.

Table 2. Various psychological theoretical explanations of technological fear with descriptions and definitions with examples seen with technologies.

Psychological Theories

Social Norm Theory-social norms are the (unspoken) 'rules' enforced by a community (Elster, 1989).

\section{Technology Example(s)}

There are a number of anecdotal narratives that have become normalized, for instance, everything posted on social media is fake (e.g., influencers discussing 'Instagram reality', where many will not admit to photoshopping images, etc.). 
Attribution Error-where the individual A friend posted a photo on Instagram of their house overestimates personal factors or behavior and with a caption stating 'Missing \#home', and found underestimates other situational factors their home was broken into. This was attributed to the (Hewstone, 1990).

photo being posted online rather than the friend living in a high-crime area with other homes being broken into fairly frequently.

Social Identity Theory — seeks to explain social Has been used to describe how echo chambers occur behavior by understanding the relationship online, whereby SIT helps explain the homophily in between self and society via a set of 'roles' (e.g., views shared online and depersonalization of an individual can be a manager and artist) (Hogg, individuals (Risius, Aydingül, \& Haug, 2019). Terry, \& White, 1995). Technophobia here might arise from in- and outgroup differences in politics and opinion (e.g., rightwing 'extremists').

Social Learning Theory - suggests that people learn not only from direct experience, but also from observation. Further, there are many The assumption that watching violent television or playing violent video games causes children to act mediation processes during learning (Bandura, 1971).

Stereotypes - conceptualized as an often rigid set of beliefs that are overly generalized and factually incorrect (Gardner, 1994).

Uncertainty - concerned with decision-making that is based on the likelihood of uncertain events, e.g., elections, stock markets. Decisions The assumption that smartphones are causing <insert negative outcome $>$ because we hear this on the news and in the media frequently.

Uncertainty of how AI will impact on the workplace, causing fear due to the concern of being replaced by a machine/robot.

and judgements are made based on data and information with limited validity, which leads to errors and poor decisions (Tversky \& Kahneman, 1973). 
Confirmation Bias - where individuals seek information or evidence that supports their own beliefs (Nickerson, 1998).

Human/Personal Autonomy and Self- It has been 'demonstrated' that large swathes of the Regulation Theory-autonomy refers to the capacity to decide our paths; to make our own decisions, and to view ourselves as our own person and self-governing agent (Buss \& Westlund, 2018).

Self-regulation theory is the process of people monitoring their behaviors or actions and modifying said behavior in order to align with goals or the intended outcomes (Bandura, 1991)
People online might go to websites and visit online communities to reinforce their beliefs (e.g., echo chambers). there is a perceived self-regulation and self-control issue, hence feeling like personal autonomy is removed, thus, we perceive, we cannot stop using our smartphones.

\section{Conceptual Shortfalls of Psychological Technology Research}

Psychological science has a strong history of being interdisciplinary, but this appears to have had little impact when considering the potential for harm or benefits from other perspectives when it comes to psychological research into new technologies (e.g., Bogen, 2017; boyd, 2014). This pathologizing of everyday behaviors is not exclusive to technology use research - it is actually a widespread issue across psychological science. Haslam (2016) initially coined the term: 'concept creep', describing how research interests in negative experience and behavior has become widespread in psychological science. Hence, there is a demonstrable increase in pathologizing everyday behaviors and experience, which in turn influences our research due to our heightened awareness of such harm (Haslam, 2016). This idea was extended to argue that concept creep can be both positive and negative, where there is potential to uncover meaningful insights into problematic behaviors. However, we argue that much technology research (and arguably wider psychological research also) falls into the realm of 'sloppy overuse of a concept,' (Cascardi \& Brown, 2016, p. 24) by academics focusing on a single negative behavior, feeling or attitude. This can, and does, undermine key features of genuine problematic behaviors and dilute interventions should they be necessary - arguably seen in the current technology addictions literature. Hence, we encounter a substantial issue of distinguishing between concept creeps and insightful expansion (Cascardi \& Brown, 2016). 
Generally speaking, technology research falls victim to concept creep, which continues to fuel questionable theoretical underpinnings, frameworks, and mechanisms that aim to explain why readily available technology (e.g., smartphones) could be harmful.

Hence, being objective and critical about technologies - particularly smartphones or social media is vital as researchers are also inherently reliant upon them (or simply researchers holding different perspectives and beliefs around digital technologies). It appears that many continue to forget the 'bigger picture' of technology and society:

'one of the most disappointing aspects of academic work in this area [...] is a general failure to think carefully about the social nature of digital technology,' (Sewlyn, 2011, p. 82).

\section{'This is the way, step inside,'}

Psychological science is looping and as the speed of technology development increases, these mistakes become more frequent and obvious to other disciplines. Psychology has a duty to understand, and where possible, predict or mitigate future problems that new technologies could bring. There is also little doubt that technology has many impacts on people and society. However, our current understanding is largely built on sand. This brings both challenges and opportunities to psychologists.

\section{Interdisciplinary approaches are key}

Psychological science has had a rich history of interdisciplinary work, yet in some areas it appears to have become even more siloed. While interdisciplinary work remains difficult (Steffes \& Valentine, 1996), it is critical to widen perspectives and take learnings from other disciplines. Alternatively, we continue to curate 'knowledge silos' that are less valuable and impactful (Obradović, 2019). There are a number of other disciplines that psychological science would take learnings from, for example, STS, communication studies, and IS (among others) already provide a number of new perspectives and ways of understanding technology and society. The following points give a brief overview of what these areas could offer:

- Science and Technology Studies (STS)

- STS takes a range of approaches, usually grounded in sociology and philosophy, to understand not only how a technology impacts individuals and society, but also how technology is inherently economic, political, and social (Mackay \& Gillespie, 1992; MacKenzie \& Wajcman, 1999). Critically, STS has tended to eschew the view that technology is neutral, instead viewing the interaction between society and technology as one that has both positive and negative impacts on human culture (e.g., Feenberg, 1993, 
2010; Geels, 2007). Although, others have then argued that technology is not neutral (nor good or bad) (Feenberg, 1993, 2010; Kranzberg, 1986) as technologies are developed and used for purposes (and generate consequences) that go beyond the initial reason for development (e.g., agricultural products to eliminate pests, then threatening wider ecological systems) (Kranzberg, 1991).

- Communication Studies

- Communication studies considers the impact of technologies through the lens of media effects research. This research was historically rooted in a stimulus-response association by which media were thought to have direct, powerful, and universal impacts on their users (Lowery \& DeFluer, 1994), although this approach (referred to pejoratively as the 'magic bullet' paradigm of media effects) is considered antiquated by contemporary communication scholars Neumann \& Guggenheim (2011). Modern approaches of communication scholars - those largely happening after the 1960s — consider media effects (of which, technology effects can be understood) as happening 'among and through a nexus of mediating factors and influences (Klapper, 1960, p. 8). For example, the theory of interactive media effects (Sundar, Jia, Waddell, \& Huang, 2015) proposes an objective consideration of the features of a given technology, and suggests that the effects of those features are dependent on both how a user response to their presence (cue processing, often through more heuristic routes) as well as a how a user engages the technology itself (actions, processed more centrally). Although certainly technophobic 'magic bullet' research agendas exist in communication, many studies are more focused on generating functional (rather than normative) models of technology's impact on users' thoughts, actions, and feelings (see Bowman, 2019).

- Information Systems (IS) (Management)

- IS has much to offer theoretically regarding fear and resistance to technology - it discusses both the opportunities and challenges of technologies within organizations (e.g., Fichman, Kohli, \& Krishnan, 2011; Hirschheim \& Newman, 1988; Kim \& Kankanhalli, 2009; Rai \& Sambamurthy, 2006). Much of this work has been informed by traditional psychological theory. For example, rational decision-making, cognitive misperceptions/biases, or psychological commitments (social norms, conflict, resistance) (e.g., Kim \& Kankanhalli, 2009). Alongside this, many authors have understood resistance and fear as a complex social phenomenon, which is often portrayed as a reaction to change (Hirschheim \& Newman, 1988) or a loss of control, which generates anxiety and defensive actions (Diamond, 1986). 
By embracing other disciplines and working collaboratively, this will enact change. While the many disciplines offer 'new' theoretical lenses, psychology must also reconsider and reevaluate the methods currently used, as this will improve and enrich psychological research (Edgerton, 1995; Piwek, Ellis, \& Andrews, 2016). By having active collaborations with computer scientists, engineers, or statisticians, we can build new tools (e.g., smartphone apps, for example: PEGLOG (location tracker for social scientists, built with security and privacy at its core), (Geyer et al., 2018), wearable devices, sensors) and develop new methods or approaches. Similarly, by taking learnings from a number of other disciplines, we can expand our qualitative work to understand attitudes and experiences with technologies, and better understand how these technologies can be harnessed for other purposes. Additionally, 'newer' methods such as text mining and computational linguistics also have much to offer technology research yet remain largely untouched within psychological science at present.

\section{Exploratory and descriptive approaches}

It is clear more descriptive or exploratory work is required to understand 'basic' interactions with technologies in daily life prior to researching its implications, yet alone developing diagnostic tools or interventions (e.g., technology 'addiction' or digital detoxes) (e.g., Harari et al., 2019). By this, we define descriptive research as research aiming to describe phenomena and characteristics of something (e.g., smartphone use) (Nassaji, 2015), which would require examination across contexts (e.g., home versus work) and over time (e.g., how do children versus adults use smartphones? How does an individual change their usage over years?) as well. This descriptive work on human computer interaction can be systematic and would allow researchers to understand if existing theories are fit for purpose (Shaw, Ellis, and Ziegler, 2018). By embracing new opportunities (as other disciplines have) the rate of progress would increase dramatically.

To give one example of where descriptive and interdisciplinary research has been effectively deployed, we are now reaching a point where groups of authors drawing similar conclusions concerning everyday technology usage (e.g., Andrews et al., 2015; Davidson \& Ellis, 2019; Ellis, 2019; Ellis, Davidson, Shaw, et al., 2019; Orben et al., 2019; Orben \& Przybylski, 2019b, 2019a). In this instance, technological developments can contribute alongside theory in this respect as our understanding of how technology shapes people and society (Baddeley, 2018; Kubovy, 2019). Descriptive work like this can also better sit alongside dynamic and fast-paced technologies that change and adapt; Facebook when it first launched is extremely different to Facebook of 2020, similarly our smartphones are extremely different from the original 'brick' mobile phones. However, we must remain careful with 'out-of-date' work that becomes 
obsolete, where direct replications may be difficult when technologies change too much (Lane, 2018). It is important to note that other fields of social science have engaged much more so with descriptive research, for example, Communications. Much of the focus has shifted towards wanting to understand what people do with various media/devices via the lens of the Uses and Gratifications paradigm (Katz, Blumler, \& Gurevitch, 1973). Hence, psychological science has much to gain from collaborations with Communications and other disciplines.

\section{Conclusion}

One might argue that many of the issues raised here are merely academic. Psychology's recent history does suggest that the research base is starting to acknowledge harm within itself. Beyond the well-documented challenges of ensuring our research practices remain open and transparent, Conflicts of interest (COI) declaration, for example, remains a key issue in the social sciences. Leading scholars having COIs are also prominent in the area of technology research, but are rarely declared (Chivers, 2019). Yet these academic issues inevitably lead to real applied harms. There has been a rise in the number of 'addiction treatment' centers, typically for various technology addictions, for example: The Center for Internet and Technology Addiction (https://virtual-addiction.com/), Net Addiction (http://netaddiction.com/). Even existing clinical centers, like the Priory, which is a leading private provider for mental health in the UK, has a section for internet addiction (https://www.priorygroup.com/addiction-treatment/internet-addiction-treatment). It is important to note that these all are expensive treatments, and yet, are based on questionable science. The real harm or worry by pathologizing new technology, which is often neglected from the literature, is that these centers provide a false face validity for treatments that are untested. This not only further detracts from real technological harms, but also saps money from individuals who would benefit from more suitable treatment. Given that psychological research may have played an indirect role in their development, the discipline also has a duty to reflect and challenge these programs if they are found to be based on flimsy evidence.

If psychology fails to reflect on its current position, a paradox will be maintained. Psychological science is well-equipped to understand how and why technology might help or harm groups and people. It also has a strong history of methodological innovation, with several journals devoted to new developments in this area (e.g., Behavior Research Methods). However, when it comes to the impact of technology itself, psychological science at present has comparatively little to contribute beyond fueling widespread moral panics. Research governed by biases distracts from other major issues affecting society. The field should now consider how it might reposition itself before attempting to convince others that every new massadopted technology is inherently harmful. 
The words of George Orwell echo far and wide. Is this a perfect description of new technology or reflective of the very systems that undermine our current understanding?

'...the machine is here, and its corrupting effects are almost irresistible.' (Orwell, 1937)

\section{References}

Albert, G., \& Lotan, T. (2018). How many times do young drivers actually touch their smartphone screens while driving?. IET Intelligent Transport Systems, 12(6), 414-419.

Andrews, S., Ellis, D. A., Shaw, H., \& Piwek, L. (2015). Beyond self-report: Tools to compare estimated and real-world smartphone use. PLoS ONE, 10(10), 1-9. https://doi.org/10.1371/journal.pone.0139004

Autor, D. H., Katz, L. F., \& Alan, B. (1998). Computing inequality: have computers changed the labor market? The Quarterly Journal of Economics, 113(4), 1169-1213.

Baddeley, A. (2018). Working Memories: Postmen, Divers and the Cognitive Revolution. Routledge.

Bandura, A. (1971). Social learning theory. Social Learning Theory, pp. 1-46. https://doi.org/10.1111/j.1460-2466.1978.tb01621.x

Bandura, A. (1991). Social cognitive theory of self-regulation. Organizational Behavior and Human Decision Processes. https://doi.org/10.1016/0749-5978(91)90022-L

Blumenthal, Ralph. 'Death Race'. The New York Times, 28 December 1976, sec. Archives. https://www.nytimes.com/1976/12/28/archives/death-race-game-gains-favor-but-not-with-thesafety-council.html.

Bogen, J. (2017). Theory and Observation in Science. In E. N. Zalt (Ed.), Stanford Encyclopedia of Philosophy. Retrieved from https://plato.stanford.edu/archives/sum2017/entries/science-theoryobservation/

Bowman, N. D. (2019). Media effects: A functional perspective. In D. Stacks, M. Salwen, \& Campbell-Eichhorn, K. (Eds.), An integrated approach to communication theory and research (pp. 223-234). New York: Routledge.

boyd, d. (2014). It's Complicated: The Social Lives of Networked Teens. In It'S Complicated: the Social Lives of Networked Teens. https://doi.org/10.1007/s10615-014-0512-3

Bracha, S., Williams, A. E., \& Bracha, A. S. (2004). Does" fight or flight" need updating?. Psychosomatics, 45(5), 448-449.

Brasington, R. (1990). Nintendinitis. New England JOurnal of Medicine, 322, 1473-1474. doi:10.1056/NEJM1990051732222020 
Buss, S., \& Westlund, A. (2018). Personal Autonomy. The Stanford Encyclopedia of Philosophy, Spring.

Cascardi, M., \& Brown, C. (2016). Concept Creep or Meaningful Expansion? Response to Haslam. Psychological Inquiry, 27, 24-28. https://doi.org/10.1080/1047840X.2016.1111123

Chivers, T. (2019). Does psychology have a conflict-of-interest problem? Nature (News Feature), 571, 20-23. https://doi.org/10.1038/d41586-019-02041-5

Davidson, B. I., \& Ellis, D. A. (2019). Social media addiction: technological déjà vu. BMJ, (365), I4277. https://doi.org/10.1136/bmj.14277

Davidson, B. I., Joinson, A. N., \& Jones, S. L., (2018), Technologically Enhanced Dating: Augmented Human Relationships, Robots, and Fantasy, in A Networked Self and Love, Routledge: USA.

Diamond, A. (1986). RESISTANCE TO CHANGE: A PSYCHOANALYTIC CRITIQUE OF ARGYRIS AND SCHONS CONTRIBUTIONS TO ORGANIZATION THEORY AND INTERVENTION MICHAEL. Journal of Management Studies, 23(5), 543-562.

Dittmar, J. E. (2011). Information technology and economic change: the impact of the printing press. The Quarterly Journal of Economics, 126(3), 1133-1172.

Edgerton, D. (1995). Technophobis then and now. Nature, 376(6542), 653-654. https://doi.org/10.1038/376653a0

Elhai, J. D., Dvorak, R. D., Levine, J. C., \& Hall, B. J. (2017). Problematic smartphone use: A conceptual overview and systematic review of relations with anxiety and depression psychopathology. Journal of Affective Disorders. https://doi.org/10.1016/j.jad.2016.08.030

Ellis, D. A. (2019). Are smartphones really that bad? Improving the psychological measurement of technology-related behaviors. Computers in Human Behavior. https://doi.org/10.1016/j.chb.2019.03.006

Ellis, D. A., Davidson, B. I., \& Kaye, L. K. (2019). Should Smartphones Be Banned for Children or Does Cyberpsychology Have a Bigger Problem? Cyberpsychology, Behavior, and Social Networking, 22(7), 508-509. https://doi.org/10.1089/cyber.2019.29152.lte

Ellis, D. A., Davidson, B. I., Shaw, H., \& Geyer, K. (2019). Do smartphone usage scales predict behaviour? International Journal of Human-Computer Studies, 130, 86-92. https://doi.org/10.31234/osf.io/6fjr7

Elson, M., Ferguson, C. J., Gregerson, M., Hogg, J. L., Ivory, J., Klisanin, D., ... Wilson, J. (2019). Do Policy Statements on Media Effects Faithfully Represent the Science? Advances in Methods and Practices in Psychological Science, 2(1), 12-25. https://doi.org/10.1177/2515245918811301 
Elster, J. (1989). Social Norms and Economic Theory. Journal of Economic Perspectives, 3(4), 99117.

Feenberg, A. (1993). Critical Theory of Technology. Oxford, UK: Oxford University Press.

Feenberg, A. (2010). Marxism and the critique of social rationality: From surplus value to the politics of technology. Cambridge Journal of Economics, 34, 37-49. https://doi.org/10.1093/cje/bep006

Fichman, R. G., Kohli, R., \& Krishnan, R. (2011). The Role of Information Systems in Healthcare: Current Research and Future Trends. Information Systems Research, 22(3), 419-428.

Fieschi, M. (2002). Information technology is changing the way society sees health care delivery. International Journal of Medical Informatics, 66(1), 85-93. https://doi.org/10.1016/S13865056(02)00040-0

Fischer, C. S. (1992). America calling: A social history of the telephone. Berkeley, CA: University of California Press.

Gardner, R. C. (1994). Stereotypes as consensual beliefs. In M. Zanna \& O. James (Eds.), The Psychology of Prejudice, vol. 7 (pp. 1-33). Hillsdale, New Jersey, USA: Lawrence Erlbaum Associates.

Gartner (2020). Gartner Hype Cycle. Gartner Inc. [WWW:] https://www.gartner.com/en/research/methodologies/gartner-hype-cycle

Geels, F. W. (2007). Feelings of discontent and the promise of middle range theory for STS: Examples from technology dynamics. Science Technology and Human Values, 32(6), 627-651. https://doi.org/10.1177/0162243907303597

Geyer, K., Ellis, D. A., \& Piwek, L. (2018). A simple location-tracking app for psychological research. Behaviour Research Methods. https://doi.org/https://doi.org/10.3758/s13428-018-1164-y

Gilman, L., Cage, D. N., Horn, A., Bishop, F., Klam, W. P., \& Doan, A. P. (2015). Tendon rupture associated with excessive smartphone gaming. Journal of American Medicine: Internal Medicine, 175(6), 1048-1049. doi: 10.1001/jamainternmed.2015.0753

Goldsworthy, A. (2011). How Smart Meters May Cause Autism and Cancer. Scientific Paradigm Review.

Goode, E., \& Ben-Yehuda, N. (1994). Moral panics: Culture, politics, and social construction. Annual Review of Sociology, 20, 149-171.

Green, F. (2012). Employee Involvement, Technology, and evolution in job skills: A Task- Based analysis. Industrial and Labor Relations Review, 65(1), 36-67. https://doi.org/10.1177/001979391206500103

Griffiths, M. D. (2005). A 'components' model of addiction within a biopsychosocial framework. Journal of Substance Use, 10(4), 191-197. 
Griffiths, M. D. (2019). The evolution of the 'components model of addiction' and the need for a confirmatory approach in conceptualizing behavioral addictions. Dusunen Adam The Journal of $\begin{array}{llll}\text { Psychiatry } \quad \text { Neurological } & \text { Sciences, } & 32, & \text { 179-184. }\end{array}$ https://doi.org/10.14744/DAJPNS.2019.00027

Harari, G. M., Müller, S. R., Stachl, C., Wang, R., Wang, W., Bühner, M., ... Gosling, S. D. (2019). Sensing Sociability: Individual Differences in Young Adults' Conversation, Calling, Texting, and App Use Behaviors in Daily Life. Journal of Personality and Social Psychology. https://doi.org/10.1037/pspp0000245

Haslam, N. (2016). Concepts of Harm and Pathology. Psychological Inquiry, 27(1), 1-17. https://doi.org/10.1080/1047840X.2016.1082418

Hewstone, M. (1990). The "ultimate attribution error"? A review of the literature on intergroup causal attribution. European Journal of Social Psychology, 20, 311-335.

Hirschheim, R., \& Newman, M. (1988). Information Systems and User Resistance: Theory and Practice. The Computer Journal, 31(5), 398-408.

Hogg, M., Terry, D., \& White, K. (1995). A tale of two theories: A critical comparison of identity theory with social identity theory. Social Psychology Quarterly, Vol. 58, pp. 255-269. https://doi.org/10.2307/2787127

Katevas, K., Arapakis, I., \& Pielot, M. (2018). Typical Phone Use Habits: Intense Use Does Not Predict Negative Well-Being. Proceedings of the 20th International Conference on HumanComputer Interaction with Mobile Devices and Services. https://doi.org/10.1145/3229434.3229441

Katz, E., Blumler, J. G., \& Gurevitch, M. (1973). Uses and Gratifications Research. The Public Opinion Quarterly, 37(4), 509-523.

Kim, H.-W., \& Kankanhalli, A. (2009). Investigating User Resistance to Information Systems Implementation: A Status Quo Bias Perspective. MIS Quarterly, 33(3), 567-582.

Klapper, J. (1960). Effects of mass communication. New York: Free Press.

Korucek, C. A. (2012). The agony and the Exidy: A history of video game violence and the legacy of Death Race.' Game Studies, 12(1)

Kranzberg, M. (1986). Technology and history: Kranzberg's laws. Technology and Culture, 27, 544560.

Kranzberg, M. (1991). Science-Technology-Society: It's as Simple as XYZ! Theory Into Practice, $30(3), 234-241$.

Kubovy, M. (2019). Lives as Collections of Strands: An Essay in Descriptive Psychology. Perspectives on Psychological Science, 1745691619887145. 
Kucharavy, D., \& de Guio, R. (2007). Application of s-shaped curves. TRIZ-Future Conference 2007: Current Scientific and Industrial Reality (pp. 81-88). Frankfurt, Germany.

Lane, B. L. (2018). Still too much of a good thing? The replication of Tong, Van Der Heide, Langwell, and Walther (2008). Communication Studies, 69(3), 294-303. https://doi.org/10.1080/10510974.2018.1463273

Lowery, S. A., \& DeFleur, M. L. (1994). Milestones in mass communication research (3rd Edition), New York: Allyn \& Bacon.

Mackay, H., \& Gillespie, G. (1992). Extending the Social Shaping of Technology Approach: Ideology and Appropriation. Social Studies of Science. https://doi.org/10.1177/030631292022004006

MacKenzie, D., \& Wajcman, J. (1999). The social shaping of technology (2nd Editio). Open University Press.

Nassaji, Hossein. (2015). Qualitative and descriptive research: Data type versus data analysis. Language Teaching Research, 19(2), 129-132, https://doi.org/10.1177/1362168815572747

Nickerson, R. S. (1998). Confirmation Bias : A Ubiquitous Phenomenon in Many Guises. Journal of General Psychology, 2(2), 175-220.

Neuman, W. R., \& Guggenheim, L. (2011). The evolution of media effects theory: A six-stage model of cumulative research. Communication Theory, 21, 169-196. doi: 10.1111/j.1468-2885.2011.01381.x

Obradović, S. (2019). Publication pressures create knowledge silos. Nature Human Behaviour, 3, 1028. https://doi.org/10.1038/s41562-019-0674-7

Orben, A., Dienlin, T., \& Przybylski, A. K. (2019). Social media's enduring effect on adolescent life satisfaction. Proceedings of the National Academy of Sciences of the United States of America, 116(21), 10226-10228. https://doi.org/10.1073/pnas.1902058116

Orben, A., \& Przybylski, A. K. (2019a). Screens, Teens, and Psychological Well-Being: Evidence From Three Time-Use-Diary Studies. Psychological Science, 30, 682-696. https://doi.org/10.1177/0956797619830329

Orben, A., \& Przybylski, A. K. (2019b). The association between adolescent well-being and digital technology use. Nature Human Behaviour, 3, 173-182. https://doi.org/10.1038/s41562-0180506-1

Orwell, G. (1937). The Road to Wigan Pier. Victor Gollancz, London: UK.

Parker, S. (1995). Science Discoveries: Alexander Graham Bell. Philadelphia, USA: Chelsea House Publishers.

Piwek, L., Ellis, D. A., \& Andrews, S. (2016). Can programming frameworks bring smartphones into the mainstream of psychological science? Frontiers in Psychology. https://doi.org/10.3389/fpsyg.2016.01252 
Plato (360 BCE). Phaedrus. (W. Jowett, trans). Cambridge, MA: MIT

Przybylski, A. K., \& Weinstein, N. (2019). Violent video game engagement is not associated with adolescents' aggressive behaviour: evidence from a registered report. Royal Society Open Science, 6(2). https://doi.org/10.1098/rsos.171474

Rai, A., \& Sambamurthy, V. (2006). Editorial Notes-The Growth of Interest in Services Management: Opportunities for Information Systems Scholars. Information Systems Research, $17(4), 327-331$.

Renstrom, J. (2020). Is secondhand screentime the new secondhand smoking? The Conversation.https://theconversation.com/is-secondhand-screen-time-the-new-secondhandsmoking-129500

Richardson, M., Hussain, Z., \& Griffiths, M. D. (2018). Problematic smartphone use, nature connectedness, and anxiety. Journal of Behavioral Addictions. https://doi.org/10.1556/2006.7.2018.10

Risius, M., Aydingül, O., \& Haug, M. (2019). Towards an understanding of conspiracy echo chambers on Facebook. Twenty-Seventh European Conference on Information Systems (ECIS2019). Stockholm-Uppsala, Sweden.

Rosen, L. D., \& Sears, D. C. (1987). Computerphobia. Behaviour Research Methods, 19(2), 167-179.

Rutledge, P. B. (2013). Arguing for media psychology as a distinct field. In K. Dill (Ed.), The Oxford handbook of media psychology (pp. 43-61). Oxford, UK: Oxford University Press.

Schink, J. C. (1991). Nintendo Enuresis. Archives of Pediatrics \& Adolescent Medicine 145(10), 1094. https://doi.org/10.1001/archpedi.1991.02160100026017.

Scott, D. T. (2018). Pathology and technology: Killer apps and sick users. New York: Peter Lang Publishing.

Sewlyn, N. (2011). Making sense of young people, education and digital technology: the role of sociological theory. Oxford Review of Education, 38(1), 81-96.

Shaw, H., Ellis, D. A., \& Ziegler, F. V. (2018). The Technology Integration Model (TIM). Predicting the continued use of technology. Computers in Human Behavior, 83, 204-214. https://doi.org/10.1016/j.chb.2018.02.001

Soper, W. B., \& Miller, M. J. (1983). Junk-time junkies: An emerging addiction among students. The School Counselor, 31(1), 40-43

Steffes, B., \& Valentine, J. (1996). The Relationship Between Organizational Characteristics and Expected Benefits in Interdisciplinary Teams. Research in Middle Level Education Quarterly, 19(4), 83-106. 
Stein, J. L. (1996). Ideology and the telephone: The social reception of a technology, London 1876-1920. Unpublished dissertation. London: University College London.

Sundar, S. S., Jia, H., Waddell, T. F., \& Huang, Y. (2015). Toward a theory of interactive media effects (TIME). In S. S. Sundar (Ed.), The handbook of the psychology of communication technology (pp. 47-86). New York: Routledge.

Tao, S., Wu, X., Zhang, S., Tong, S., Hao, J., \& Tao, F. (2017). Association of alcohol use with problematic mobile phone use and depressive symptoms among college students inAnhui, China. Journal of Public Health (Germany). https://doi.org/10.1007/s10389-016-0766-z

Thierer, A. (2013). Technopanics, threat inflation, and the danger of an information technology precautionary principle. Minn. JL Sci. \& Tech., 14, 309.

Tversky, A., \& Kahneman, D. (1973). Availability: A Heuristic for Judging Frequency and Probability. Cognitive Psychology, 5, 207-232.

Twenge, J. M. (2019). More Time on Technology, Less Happiness? Associations Between DigitalMedia Use and Psychological Well-Being. Current Directions in Psychological Science. https://doi.org/10.1177/0963721419838244

U.S. Department of Education. (1982). Television and Behavior. Ten Years of Scientific Progress and Implications for the Eighties. In US Dept of Health and Human Services.

UK Parliament. (2018). Impact of social media and screen-use on young people's health inquiry launched. Retrieved August 24, 2018, from UK Parliament: UK Government website: https://www.parliament.uk/business/committees/committees-a-z/commons-select/science-andtechnology-committee/news-parliament-2017/social-media--young-peoples-health-inquirylaunch-17-19/

Van Rooij, A. J., Ferguson, C. J., Colder Carras, M., Kardefelt-Winther, D., Shi, J., Aarseth, E., ... \& Deleuze, J. (2018). A weak scientific basis for gaming disorder: Let us err on the side of caution. Journal of behavioral addictions, 7(1), 1-9.

Wolniewicz, C. A., Tiamiyu, M. F., Weeks, J. W., \& Elhai, J. D. (2018). Problematic smartphone use and relations with negative affect, fear of missing out, and fear of negative and positive evaluation. Psychiatry Research.https://doi.org/10.1016/j.psychres.2017.09.058 